\title{
NEPP: CONTRIBUIÇÕES DA EXTENSÃO UNIVERSITÁRIA POR MEIO DE CONSULTORIA À ASSOCIAÇÃO DOS DEFICIENTES FÍSICOS DO RN
}

\author{
Manuela Hannah de Mendonça Freire; Jadson Silva Pereira; Denise Cristina Momo; Marlene Medeiros \\ hannahdmf@gmail.com; jadsonsilva133@gmail.com; denise.cristina@ifrn.org.br; \\ marlene.medeiros@ifrn.edu.br
} Instituto Federal de Educaçao, Ciëncia e Tecnologia do Rio Grande do Norte - IFRN - Campus Natal Zona Norte

DOI:10.15628/diálogos.2018.6738

Artigo submetido em dez/2017 e aceito em jul/2018

\section{RESUMO}

O presente artigo trata do relato de experiência da ação realizada pelo núcleo de extensão e prática profissional (NEPP), do IFRN Campus Natal Zona Norte, na associação dos deficientes físicos do Rio Grande do Norte (ADEFERN). O objetivo da ação foi de aplicar os conhecimentos técnicos dos alunos do curso tecnólogo em Marketing, de modo a identificar os principais problemas da ADEFERN e minimizá-los por meio da prática profissional. A metodologia utilizada foi a de consultoria. Esta foi iniciada com o diagnóstico da instituição por meio da ferramenta de análise matriz SWOT e culminou em posteriores ações de melhoria. Como principais contribuições para instituição apontam-se: a identificação dos pontos fortes e fracos, ameaças e oportunidades; o desenvolvimento da marca para a rádio; e a elaboração da missão, visão e valores. Para o NEPP a parceria contribuiu com o enriquecimento dos conhecimentos dos alunos e maior interação escola/sociedade.

PALAVRAS-CHAVE: Prática Profissional. Consultoria. Associação dos deficientes.

\section{INTRODUÇÃO}

O Projeto Núcleo de Extensão e Prática Profissional - NEPP: Studio Criativo consiste na criação de um ambiente propício a aplicação dos conhecimentos técnicos adquiridos no curso superior tecnólogo em Marketing do Instituto Federal do Rio Grande do Norte - Campus Natal Zona Norte, por meio do desenvolvimento da prática profissional. O projeto tem como objetivo a prestação de serviços gratuitos à comunidade, tendo como finalidade ampliar a oferta de prática profissional, para os alunos do IFRN/ZN, sob orientação de professores da área, em atividades 
relativas à sua formação profissional, contribuindo assim para o aperfeiçoamento e ampliação dos conhecimentos adquiridos nas atividades do processo de ensino aprendizagem (IFRN, 2017). A criação do NEPP: Studio Criativo vem corroborar com o atendimento da Meta 12, estratégia 12.7 da Lei 13.005/2014 do Plano Nacional de Educação: "assegurar, no mínimo, 10\% (dez por cento) do total de créditos curriculares exigidos para a graduação em programas e projetos de extensão universitária, orientando sua ação, prioritariamente, para áreas de grande pertinência social" (Brasil, 2014).

Atualmente, temos no campus Natal Zona Norte 156 alunos matriculados no curso superior de tecnologia em Marketing, motivo mais que especial para a implementação do NEPP. Assim, o presente artigo tem por objetivo relatar a experiência da ação de consultoria realizada na ADEFERN, por meio do convênio entre esta e o NEPP, buscando resultados viáveis dentro dos ensinamentos adquiridos em sala.

\section{CONTEXTO}

A Associação dos Deficientes Físicos do Rio Grande do Norte (ADEFERN) foi fundada em 11 de dezembro de 1981 e está localizada na Zona Norte de Natal na Rua Cariacica № 2000 no Conjunto Santarém no Bairro Potengi. É uma entidade civil assistencial e filantrópica que cumpre seus objetivos sociais através de parcerias com pessoas físicas e jurídicas da sociedade civil, sendo esta última sua maior parceira, garantindo a existência e funcionalidade da instituição, no que se refere ao atendimento das pessoas com deficiência no Estado (ADEFERN, 2013).

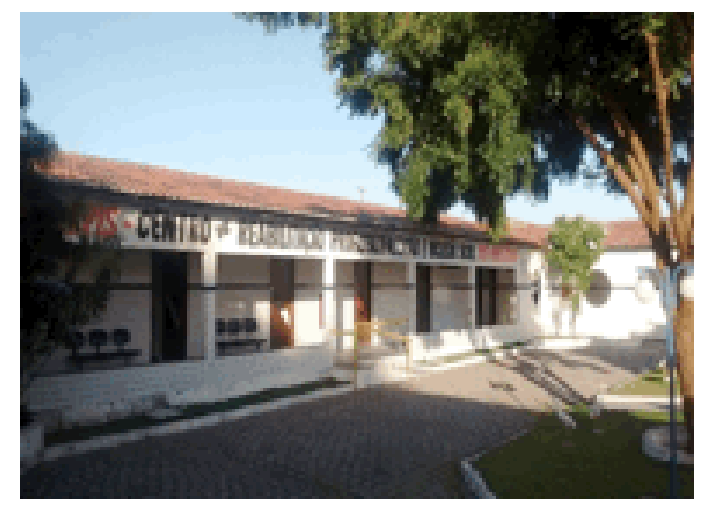

Foto 1 - Sede da ADEFERN

Fonte: NEPP - Studio Criativo, 2017 


\section{ISSN - 2447-7869}

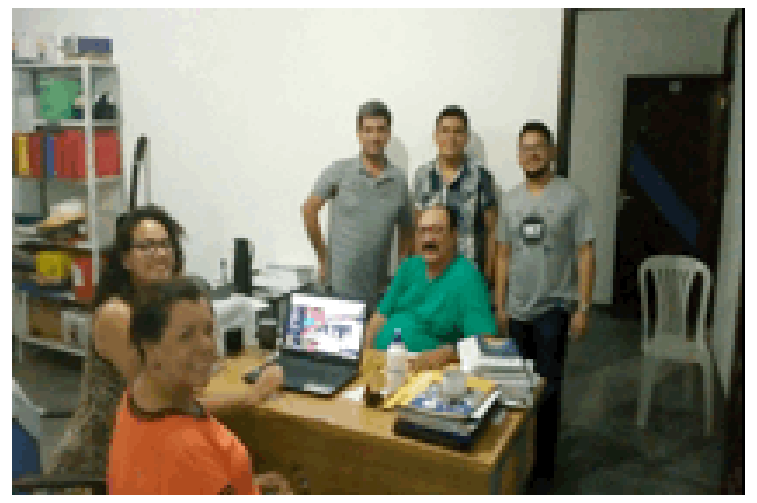

Foto 2 - Apresentação do plano de ação do NEPP ao gestor da ADEFERN

Fonte: NEPP - Studio Criativo, 2017

A instituição é dirigida e fiscalizada por pessoas com deficiências que compõe a sua diretoria executiva e o seu conselho fiscal. Atualmente possui 18 funcionários contratados, além de voluntários provenientes de parcerias com faculdades de fisioterapia. Prestam serviços de reabilitação físico motora, atendimento odontológico, psicológico, encaminhamento para o mercado de trabalho, encaminhamento para comprovação de deficiência, encaminhamentos para obtenção de gratuidades, cursos de capacitação e qualificação profissional através de parceria com o Sistema "S", encaminhamento para obtenção benefício de prestação continuada da previdência social, dentre outras orientações, que demonstram a diversidade de atendimentos (ADEFERN, 2013).

Com 36 anos de existência, a ADEFERN possui quatro mil associados cadastrados aos serviços. Tornou-se uma referência na inclusão social, cumprindo a missão para qual foi criada e baseada em quatro pilares fundamentais: socialização, reabilitação, qualificação profissional e inserção no mercado de trabalho (ADEFERN, 2013).

\section{METODOLOGIA}

A proposta de intervenção surgiu a partir do diagnóstico feito na instituição em seis visitas ao empreendimento. Os dados foram coletados por meio de entrevistas com os dirigentes, aplicação de questionário semiestruturado e registro das instalações realizadas por meio de observação.

Os dados foram inseridos no plano de diagnóstico do Studio Criativo, com análise de micro e macro ambiente. Para tal, foi realizada uma avaliação das forças (Strengths) e fraquezas (Weakness) internas à instituição, bem como, ameaças (Threats) e oportunidades (Opportunities) provenientes do ambiente externo, conhecida por matriz SWOT.

A consultoria teve como foco o planejamento de ações possíveis de serem aplicadas, levando em conta a disponibilidade da instituição e suas necessidades mais relevantes. 0 projeto foi desenvolvido entre os meses de julho a novembro de 2017, culminando na apresentação dos 
resultados na SEMARK/2017 (Semana de Marketing do IFRN), que contou com a presença do gestor da ADEFERN, validando a importância das ações.

As próximas seções irão apresentar as ações realizadas pelo NEPP- Studio Criativo como contribuições para ADEFERN.

\section{ANÁLISE SWOT}

Para Andion e Fava (2003) a análise dos pontos fortes e fracos da organização e das ameaças e oportunidades, por meio da matriz SWOT, possibilita ao gestor identificar suas prioridades e traçar estratégias para melhor desenvolvê-las.

Na ADEFERN a SWOT foi analisada baseada nas entrevistas com os gestores. 0 Quadro 1 , mostra os resultados da análise. \\ FORÇAS \\ - Referência na fiscalização de acessibilidade; \\ - Não envolvimento com o meio político-partidário; \\ - Encaminhamento de 800 a 1000 pessoas ao mercado de trabalho por ano; \\ - Conhecimento das leis que afetam a vida dos deficientes no município e estado; \\ - Parcerias com faculdades para estágios voluntários na instituição.}

FRAQUEZAS

- Falta de planejamento das ações e campanhas do telemarketing, além de definição de metas inalcançáveis;

- Falta de comunicação adequada para com os usuários, no que se refere ao engajamento destes em tornar público o importante papel da organização na sociedade;

- Falta de planejamento de conteúdo que apresente a comunidade o trabalho da instituição em prestar assistência aos usuários;

- Falta de diversificação de parcerias para poder se mostrar mais atuante perante toda a cidade.

\section{AMEAÇAS}

- Alto índice de inadimplência por parte dos associados;

- Alto valor social agregado à causa, de modo que permite maior participação da população na luta pela manutenção da Associação;

- As mídias digitais proporcionam menor custo com divulgação, acesso facilitado às informações, network e maior credibilidade;
- Falta de responsabilidade dos associados para com a instituição em propagar e manter a Associação;

- A atuação de entidades fraudulentas no mercado provoca falta de credibilidade social;

- Crise econômica brasileira e desemprego em massa têm dificultado a atuação da sociedade civil na manutenção da causa;

- Fortes concorrentes já estabilizados no mercado filantrópico. 
A partir da análise SWOT foi possível perceber que a instituição não se comunica de forma efetiva com seu público-alvo, que são os usuários, os doadores e as empresas. A ADEFERN, apesar de ter um trabalho relevante para sociedade, não divulga seus resultados. Financeiramente, o setor de telemarketing vem sofrendo com a pressão da grande demanda por metas maiores e inalcançáveis, diminuindo a produtividade das atendentes e ocasionando a demissão de quase metade da equipe.

\subsection{DESENVOLVIMENTO DA MARCA PARA A WEB RÁDIO}

A Web Rádio começou a ser transmitida via link de internet no dia $1^{\circ}$ de agosto de 2017 e se fez necessária à criação de uma marca para dar visibilidade ao projeto.

De acordo com Perotto (2007) as marcas se inserem e se localizam na esfera cultural e ideológica, onde atual como vetores de delimitação, diferenciação e distinção. Com base na marca institucional, foi feita uma marca para a Web Rádio ADEFERN (Figura 1). Foi pensada para fazer referência ao deficiente e mostrar que todos merecem ouvir músicas de qualidade e notícias que sejam direcionadas a este público.

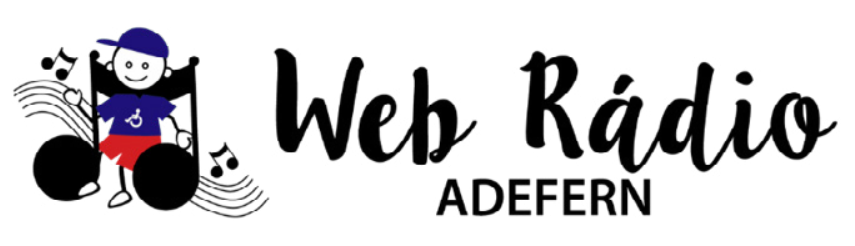

Figura 1 - Marca da Rádio

Fonte: NEPP Studio Criativo, 2017

\subsection{MISSÃO, VISÃO E VALORES}

A ADEFERN já havia preparado um ideal de missão, mas que não refletia o papel social da instituição. $O$ Studio Criativo reestruturou a mesma dando ênfase a responsabilidade com a inclusão social dos deficientes. Já para a Visão, foram tratados os objetivos de longo prazo da instituição. Em relação aos valores, foi destacado os princípios éticos que norteiam a prática da ADEFERN, conforme destacado abaixo:

Missão: Ser referência na inclusão social de pessoas com deficiência, tendo seu trabalho baseado em quatro pilares fundamentais: socialização, reabilitação, qualificação profissional e inserção no mercado de trabalho produtivo/competitivo.

Visão: Se consolidar como uma instituição que promove a socialização e o desenvolvimento 
das pessoas com deficiência, por meio da integração com a sociedade, promovendo uma rede colaborativa.

Valores:

INCLUSÃO SOCIAL

TRANSPARÊNCIA

COMPROMETIMENTO COM A CAUSA

VALORIZAÇÃO DO COLABORADOR

QUALIDADE NO ATENDIMENTO

INTEGRIDADE

RESPEITO

\subsection{MÍDIAS SOCIAIS COMO INSTRUMENTO DE INTEGRAÇÃO E RELACIONAMENTO}

Inclusão e relacionamento são conceitos interligados, visto que, o marketing de relacionamento é um "processo contínuo de criação de novos valores com clientes individuais e o compartilhamento de seus benefícios durante uma vida toda de parceria" (GORDON, 1999).

Buscando utilizar o Whatsapp como um novo canal de interação com o público interno (colaboradores e voluntários) e externo (associados, doadores e empresas), as ações na mídia social incluem devolutivas semanais dos tratamentos, atendimento ao cliente online, canal para captação de recursos através de novos doadores, meio de divulgação das campanhas institucionais e pontuais. Trazendo um número maior de pessoas atingidas pela interação da ADEFERN junto à sociedade e fortalecendo o Marketing de relacionamento entre a instituição e seus públicos. 0 plano objetiva integralizar todas as informações vindas do telemarketing, fan Page do facebook, whatsapp, instagram e mural interno para propor uma comunicação integrada e planejada, formulada para cada tipo de público.

Como recomendação futura, a consultoria indica o planejamento e adequação do telemarketing, as questões de metas alcançáveis facilitarão a motivação das atendentes, permitindo uma sensação de dever cumprido ao longo do tempo de campanha.

\section{CONCLUSÃO}

O projeto de consultoria na ADEFERN proporcionou aos alunos do curso de marketing do IFRN Natal Zona Norte a possibilidade de prática dos conhecimentos adquiridos em sala e a ratificação de habilidades necessárias ao profissional desta área no atendimento, desenvolvimento de planos e efetivação de ações para um empreendimento real que não teria condições de contratar tal serviço. Para os alunos o ganho é tanto em nível de conhecimento, quanto na confiança de fazer um bom trabalho e levar isso para o mercado como um profissional mais assertivo e flexível. Para o IFRN o retorno vem por meio de conexão com os empreendimentos da região e 
possibilidade de parcerias de estágio.

Quanto à ADEFERN, o ganho é a oportunidade de receber serviços de marketing para o desenvolvimento de suas atividades, aumentando o nível de serviço e a conexão com seus públicos e a sociedade de forma geral.

\section{REFERÊNCIAS BIBLIOGRÁFICAS}

ADEFERN. História da ADEFERN. Blogspot. Abr 2013. Disponível em:<http://adefern.blogspot. com.br/2013/04/historia-da-adefern.html. >. Acesso em 24 dez. 2017.

ANDION, Maria Carolina. FAVA, Rubens. Gestão empresarial / Fae School. Curitiba: Associação Franciscana de Ensino Bom Jesus, 2003.

BRASIL. Lei n 13.005 , de 25, de junho de 2014. Plano Nacional da Educação. Brasília, DF, jun 2014. Disponível em:< <http://www.planalto.gov.br/ccivil_03/_ato2011-2014/2014/lei/l13005. htm> Acesso em 23 dez. 2017.

GORDON, Ian. Marketing de Relacionamento, Estratégias, Técnicas e Tecnologias para Conquistar Clientes e Mantê-los para Sempre: São Paulo. Editora Futura, 1999.

IFRN. Projeto de Extenção Núcleo de Extensão e Prática Profissional - NEPP: Studio Criativo. Disponível em:< https://suap.ifrn.edu.br/projetos/projeto/3031/?tab=dados_projeto>. Acesso em 20 dez. 2017.

PEROTTO. Evandro R. Conceituando a marca pela enunciação: Uma proposta do campo da comunicação. Dissertação (Mestrado em Ciências da comunicação). - Faculdade de Comunicação, Universidade de Brasília. Brasília, p.99. 2007. 